\title{
A rose by any other name: Marginal gains of enhanced recovery after surgery in video-assisted thoracic surgery perioperative care
}

\author{
Biniam Kidane, MD, MSc, FRCSC \\ From the Section of Thoracic Surgery, Department of Surgery, Max Rady College of Medicine, University of \\ Manitoba, Winnipeg, Manitoba, Canada. \\ Disclosures: Author has nothing to disclose with regard to commercial support. \\ Received for publication Aug 24, 2017; accepted for publication Aug 28, 2017; available ahead of print Sept 28, \\ 2017. \\ Address for reprints: Biniam Kidane, MD, MSc, FRCSC, Health Sciences Centre, GE-611, 820 Sherbrook St, \\ Winnipeg, Manitoba R3A-1R9, Canada (E-mail: bkidane@hsc.mb.ca). \\ J Thorac Cardiovasc Surg 2017;154:2082-3 \\ $0022-5223 / \$ 36.00$ \\ Copyright (c) 2017 by The American Association for Thoracic Surgery \\ http://dx.doi.org/10.1016/j.jtcvs.2017.08.092
}

What's in a name? That which we call a rose

By any other name would smell as sweet. -William Shakespeare

Romeo and Juliet, Act II, scene 2, lines 45-46

Enhanced recovery after surgery (ERAS) represents a success story in peri-operative care. ${ }^{1}$ ERAS programs as organizational practices have become ingrained in many hospitals. In this issue of the Journal, Brunelli and colleagues $^{2}$ present a timely study on whether addition of ERAS is beneficial in the modern era of video-assisted thoracic surgery (VATS). With a pre/post design with a washout period of 1 month, Brunelli and colleagues ${ }^{2}$ compared outcomes of VATS lobectomy in a high-volume general thoracic unit in the period before and after the institution of a formal ERAS program. The ERAS literature in thoracic surgery is limited and focused on patients undergoing thoracotomy, demonstrating shorter length of stay as the only significant advantage. ${ }^{2,3}$ It is unclear whether this advantage would apply to VATS. ${ }^{3}$

Brunelli and colleagues ${ }^{2}$ found no differences in incidence of cardiopulmonary complications, mortality, length of stay, or readmission rate between ERAS and pre-ERAS time periods. They correctly posit that the failure to detect a difference may be because pre-ERAS practices were similar to ERAS practices. This possibility underscores a major caveat to any study comparing pre-ERAS and postERAS outcomes in such a patient population: the interventions and cointerventions are often too similar between groups. This lends itself to a "null effect" force that systematically biases such studies against ERAS and that is further compounded by 2 other major factors: (1) short washout period and (2) unclear degree of protocol adherence. If there is an abrupt switchover from non-ERAS to ERAS without a reasonable transition or washout period, this has the effect of reducing the chances of detecting any real additive effect or value of ERAS because ERAS may not have not fully

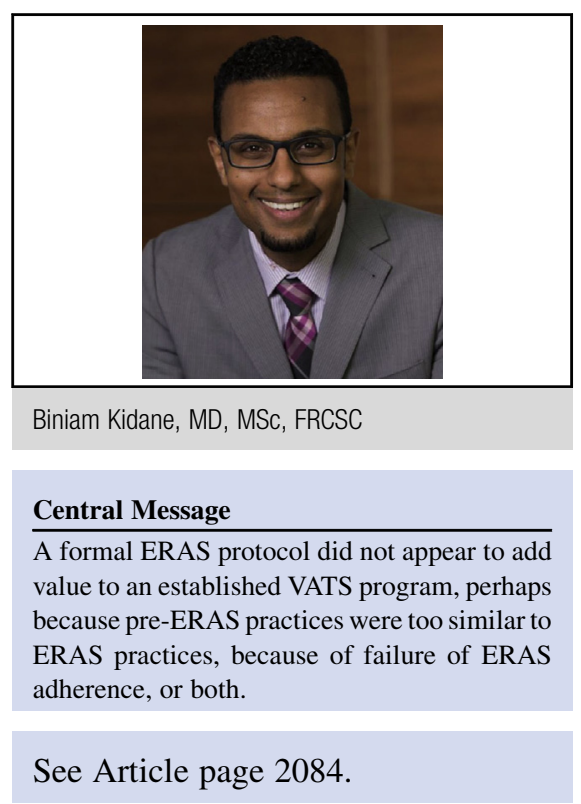

been established. It is unclear how long a transition or washout period is required to get adequate ERAS penetrance and adherence. Most would probably argue, however, that it takes longer than the 1 month reported in this study. Related to this issue is that of assessment of ERAS adherence. The primary message of the study is that ERAS was not associated with improved outcomes and was more costly, with the consequent inference being that the cost may not be justified. Without a detailed and objective assessment of adherence to the ERAS protocols, it is difficult to infer whether the results reflect a failure of ERAS or rather a failure of ERAS implementation. Brunelli and colleagues ${ }^{2}$ note that "adherence to ERAS was monitored by a dedicated" ERAS nurse. Readers need to decide whether the monitoring reported by Brunelli and colleagues ${ }^{2}$ meets the "detailed and objective assessment" criterion, and this may be difficult without any reporting of adherence metrics. Unfortunately, the short washout period and the limited reporting of ERAS adherence may be compounding the potential bias. The shorter the washout period, the more important it becomes to demonstrate objectively that ERAS protocol adherence is high.

Some caveats highlighted by Brunelli and colleagues ${ }^{2}$ warrant reiteration. Patient quality of life and satisfaction were not assessed, and these might actually be better with 
ERAS. An improvement in these alone would likely justify the cost. Brunelli and colleagues ${ }^{2}$ also posit that ERAS may have discernible benefits relative to usual care in lower-volume units that do not already have perioperative care practices similar to those in the study. Having trained and worked in multiple settings across Canada, the perioperative practices I have encountered have been quite similar to the pre-ERAS practices of Brunelli and colleagues. ${ }^{2}$ Furthermore, these practices have never been explicitly adopted or labeled as formal ERAS protocols. Having wrestled with the methodologic issues, this begs the philosophical question of whether we believe ERAS by any other name could still function as well.

\section{References}

1. Kehlet H, Wilmore DW. Evidence-based surgical care and the evolution of fasttrack surgery. Ann Surg. 2008;248:189-98.

2. Brunelli A, Thomas C, Dinesh P, Lumb A. Enhanced recovery pathway versus standard care in patients undergoing video-assisted thoracoscopic lobectomy. $J$ Thorac Cardiovasc Surg. 2017; 154:2084-90.

3. Fiore JF Jr, Bejjani J, Conrad K, Niculiseanu P, Landry T, Lee L, et al. Systematic review of the influence of enhanced recovery pathways in elective lung resection. $J$ Thorac Cardiovasc Surg. 2016;151:708-15. 